\title{
Paclitaxel suppresses proliferation and induces apoptosis through regulation of ROS and the AKT/MAPK signaling pathway in canine mammary gland tumor cells
}

\author{
XIAOLI REN, BINGBING ZHAO, HONGJIAN CHANG, MIN XIAO, YUHONG WU and YUN LIU \\ Department of Veterinary Surgery, College of Veterinary Medicine, \\ Northeast Agricultural University, Harbin, Heilongjiang 150030, P.R. China
}

Received October 10, 2017; Accepted March 7, 2018

DOI: $10.3892 / \mathrm{mmr} .2018 .8868$

\begin{abstract}
Paclitaxel is a diterpenoid compound, derived from the pacific yew (Taxus brevifolia) berry, which exhibits antineoplastic effects against various types of cancer. However, the antitumor effects and the molecular mechanisms of paclitaxel on canine $\mathrm{CHMm}$ cells remain to be elucidated. The aim of the present study was to investigate the antitumor effects of paclitaxel on $\mathrm{CHMm}$ cells and identify relevant signal transduction pathways modulated by paclitaxel using multiple methods including MTT assay, flow cytometry, acridine orange/ethidium bromide staining, transmission electron microscopy, determination of cellular reactive oxygen species (ROS), superoxide dismutase (SOD) and malondiadehyde (MDA) and western blotting, the data indicated that paclitaxel decreased cell viability, induced $\mathrm{G}_{2} / \mathrm{M}$-phase cell cycle arrest, suppressed the expression of cyclin B1 and induced apoptosis in a dose-dependent manner. In addition, paclitaxel upregulated the expression of Bax and cytochrome $\mathrm{c}$, but reduced expression of apoptosis regulator Bcl-2, resulting in activation of caspase-3, chromatin condensation, karyopyknosis, intracellular vacuolization, increased production of ROS and MDA, and decreased activity of SOD. However, these effects were inhibited when CHMm cells were treated with $\mathrm{N}$-acetyl-L-cysteine. Furthermore, treatment with paclitaxel inhibited the level of of phospho (p)-RAC- $\alpha$ serine/threonine-protein kinase (AKT) and p-ribosomal protein S6 kinase proteins, and promoted phosphorylation of P38 mitogen-activated protein kinase (MAPK) and p-90 kDa ribosomal protein S6 kinase 1 proteins in $\mathrm{CHMm}$ cells. It was observed that paclitaxel in combination with pharmacological
\end{abstract}

Correspondence to: Professor Yun Liu, Department of Veterinary Surgery, College of Veterinary Medicine, Northeast Agricultural University, 600 Changjiang Street Xiangfang, Harbin, Heilongjiang 150030, P.R. China

E-mail: liuyun@neau.edu.cn

Key words: paclitaxel, CHMm cells, apoptosis, reactive oxygen species, signal transduction inhibitors of the P38 and phosphatidylinositol-4,5-bisphosphate 3-kinase (PI3K) signaling pathways (SB203580 and LY294002, respectively) exerted synergistic inhibitory effects on the proliferation of the CHMm cells. The results of the present study demonstrated that paclitaxel inhibited tumor cell proliferation by increasing intrinsic apoptosis through inhibition of the PI3K/AKT signaling pathway and activation of MAPK signaling pathway in CHMm cells.

\section{Introduction}

Mammary gland tumors are among the most common malignant tumors with high morbidity among female canines $(1,2)$. As previously determined by histological examination, $50 \%$ of cases are malignant (2). Metastasis is a primary cause of treatment failure and mortality in human and veterinary patients (3). Because canines and humans live in the same environment and have similar genetic profiles, canine mammary gland neoplasia can serve as a model to study human mammary gland tumors (3). Surgical resection and chemotherapy are the most commonly used methods of clinical treatment of mammary gland tumors (3-5). Paclitaxel belongs to the class of diterpenoid compounds (mitotic inhibitors) derived from Taxus brevifolia, exerting efficient, broad-spectrum chemotherapeutic effects against various cancer types, including human ovarian cancer $(6,7)$, breast cancer $(8,9)$, gastric cancer $(10)$ and other malignancies $(11,12)$. The molecular formula of paclitaxel is $\mathrm{C}_{47} \mathrm{H}_{51} \mathrm{NO}_{14}$ and the relative molecular mass is 853.890. As an antimicrotubule agent, paclitaxel has been demonstrated to arrest the $\mathrm{G}_{2} / \mathrm{M}$-phase transition, interfere with several signal transduction pathways and induce apoptosis through the stabilization of microtubules $(13,14)$. However, which signaling pathways are altered by paclitaxel to induce the antitumor effects in canine mammary gland tumors remains to be elucidated.

Previous studies have demonstrated that chemotherapeutic drugs control growth of cancerous tissue through induction of apoptosis $(10,12,13,15)$. Therefore, the assessment of apoptosis following treatment with a novel chemotherapeutic drug is a marker of efficacy (16). Paclitaxel induces apoptosis in multiple cell types through different signal transduction pathways, including the phosphatidylinositol-4,5-bisphosphate 
3-kinase $(\mathrm{PI} 3 \mathrm{~K}) / \mathrm{RAC}-\alpha$ serine/threonine-protein kinase (AKT) pathway (17), the epidermal growth factor receptor pathway (12), and the mitogen-activated protein kinase (MAPK) pathway (18). Targeted inhibition of phosphorylated-phosphatidylinositol-3-kinase (p-PI3K) was demonstrated to enhance the induction of apoptosis and increase the sensitivity of paclitaxel-resistant ovarian cancer cells to treatment (19). MAPK signaling is a redox-sensitive signaling pathway (20). Oxidative stress can regulate cell proliferation, differentiation and apoptosis through the activation of the MAPK signaling pathway (21). It has been previously reported that elevated levels of reactive oxygen species (ROS) can increase the phosphorylation of JNK, P38 MAPK and extracellular signal-regulated kinase $1 / 2$, regulate the expression of $\mathrm{Bcl}-2$ family proteins and mitochondrial membrane depolarization, ultimately resulting in apoptosis $(19,22)$. Although these processes are generally well understood, the mode of action of paclitaxel in the context of canine mammary gland tumors remains to be elucidated.

The present study aimed to determine the mechanism underlying the antitumor effect of paclitaxel and the role of the AKT/MAPK signal transduction pathway in CHMm cells in vitro, in order to provide theoretical and experimental basis for clinical applications and further research.

\section{Materials and methods}

Cell culture. Canine CHMm cell line was kindly provided by the Department of Veterinary Medical Sciences, University of Tokyo (Tokyo, Japan). Cells were cultured in Dulbecco's modified Eagle's medium (DMEM; Gibco; Thermo Fisher Scientific, Inc., Waltham, MA, USA) supplemented with $10 \%$ fetal bovine serum (FBS; Hyclone; GE Healthcare Life Sciences; Logan, UT, USA), 2 mM L-glutamine, $1 \mathrm{mM}$ non-essential amino acids (Gibco; Thermo Fisher Scientific, Inc.), antibiotics $[100 \mathrm{U} / \mathrm{ml}$ penicillin, $100 \mu \mathrm{g} / \mathrm{ml}$ streptomycin, $2.5 \mu \mathrm{g} / \mathrm{ml}$ amphotericin B (all Beyotime Institute of Biotechnology, Shanghai, China) $]$ at $37^{\circ} \mathrm{C}$ in humidified air with $5 \% \mathrm{CO}_{2}$. All experiments were performed using cells in the phase of logarithmic growth.

Drug treatment. Paclitaxel (Sigma-Aldrich; Merck KGaA, Darmstadt, Germany) was dissolved in dimethylsulphoxide (DMSO; Sigma-Aldrich; Merck KGaA) at a concentration of $50 \mathrm{mg} / \mathrm{ml}$ and protected from exposure to light and stored at $-80^{\circ} \mathrm{C}$. Prior to use, the stock paclitaxel solution was further diluted with serum-free DMEM into the concentrations of $0,0.01,0.1$ and $1 \mu \mathrm{M}$. The final concentrations of DMSO in each sample was $<0.05 \%$.

Cell viability assays. CHMm cells were collected during the exponential growth phase by trypsinization ( $0.25 \%$ trypsin; Beyotime Institute of Biotechnology) and cell densities were adjusted to $1 \times 10^{4} / \mathrm{ml}$ suspensions. The cells were seeded into 96-well culture plates at a volume of $200 \mu \mathrm{l} /$ well and incubated at $37^{\circ} \mathrm{C}$ in $5 \% \mathrm{CO}_{2}$ for $24 \mathrm{~h}$. The experimental groups were treated with different concentrations of paclitaxel $(0,0.01$, 0.1 and $1 \mu \mathrm{M}$ ) and other treatments to assess synergistic effects, including $20 \mu \mathrm{M}$ LY294002 or SB203850 (PI3K/AKT inhibitor and P38 inhibitor, respectively; both Beyotime
Institute of Biotechnology) for $24 \mathrm{~h}$. MTT (100 $\mu \mathrm{l} ; 5 \mathrm{mg} / \mathrm{ml}$; Sigma-Aldrich; Merck KGaA) was added to each well and incubated for another $4 \mathrm{~h}$. The supernatants were discarded and $150 \mu \mathrm{l}$ DMSO was added while the cells were incubated in the dark for $10 \mathrm{~min}$. Optical density (OD) values was measured at a reference wavelength of $490 \mathrm{~nm}$, and a detection wavelength of $570 \mathrm{~nm}$. Cell viability values were calculated using the following formula: Cell viability rate $(\%)=\left(O D_{\text {experimental }}\right.$ group $\left.-\mathrm{OD}_{\text {blank group }}\right) /\left(\mathrm{OD}_{\text {normal control group }}-\mathrm{OD}_{\text {blank group }}\right) \times 100$.

Detection of lactate dehydrogenase activity ( $L D H)$. The activity of $\mathrm{LDH}$ was measured using the $\mathrm{LDH}$ release assay kit (Beyotime Institute of Biotechnology), according to the manufacturer's protocol. Cells $\left(3 \times 10^{4} ; 200 \mu \mathrm{l} /\right.$ well $)$ were treated with various concentrations of paclitaxel for $24 \mathrm{~h}$ and cell supernatants were then harvested by centrifugation at $400 \mathrm{x} g$ for $5 \mathrm{~min}$ at room temperature. The resulting culture supernatants were added to black to 96-well culture plates (120 $\mu \mathrm{l} /$ well). Absorbance value was measured at a wavelength of $490 \mathrm{~nm}$ in a microplate reader.

Morphological observation of apoptotic cells. Paclitaxel-treated and untreated cells were removed from culture plates by digestion with $0.25 \%$ trypsin. The cells were washed with PBS and cell densities were adjusted to $1 \times 10^{6} / \mathrm{ml}$ in PBS, $20 \mu \mathrm{l}$ acridine orange/ethidium bromide (AO/EB; 1:1; Sigma-Aldrich; Merck $\mathrm{KGaA}$ ) staining fluid was added to each milliliter of PBS at room temperature for 2-5 min. Apoptosis was assessed using a fluorescent microscope (Nikon Corporation, Tokyo, Japan). A subset of the collected cells was fixed in $2.5 \%$ glutaraldehyde overnight at $4^{\circ} \mathrm{C}$, washed thrice with PBS (pH 7.2) and stained with $2 \%$ osmium tetroxide at room temperature for $1.5 \mathrm{~h}$. The samples stained with osmium tetroxide were subsequently dehydrated with graded ethanol and immersed in pure acetone. Subsequently, the samples were embedded in an epoxy resin mixture. The blocks were sectioned using Ultracut E ultra-thin slicer, with a section thickness of 5-7 $\mu \mathrm{m}$. The sections were subsequently stained with $3 \%$ uranyl acetate and lead citrate at $25^{\circ} \mathrm{C}$ for $15-20 \mathrm{~min}$, washed with double distilled water and observed by transmission electron microscopy (TEM; Philips Medical Systems B.V., Eindhoven, The Netherlands).

Cell cycle analysis. CHMm cells were treated paclitxel for $24 \mathrm{~h}$, as described above. Following the treatment period, cells were dissociated from the culture plates using $0.25 \%$ trypsin, collected and rinsed with cold PBS. Subsequently, the cells were fixed with ice-cold $70 \%$ ethanol and incubated at $4{ }^{\circ} \mathrm{C}$ overnight. The cells were subsequently re-suspended in cold PBS and incubated with $1 \mathrm{ml}$ propidium iodide (PI) staining liquid (containing $50 \mu \mathrm{g} / \mathrm{ml}$ propidium iodide and $50 \mu \mathrm{g} / \mathrm{ml}$ RNase A; Beyotime Institute of Biotechnology) at room temperature for $1 \mathrm{~h}$ in the dark. The distribution of the cell cycle phase was evaluated by flow cytometer (BD Biosciences, Franklin Lakes, NJ, USA) using Modfit LT 4.0 software (Verity Software House, Inc., Topsham, ME, USA).

Analysis of cell apoptosis. CHMm cells were seeded in 6 -well plates at a density of $3 \times 10^{4} /$ well and incubated overnight at $37^{\circ} \mathrm{C}$. Culture medium was replaced with one of the described above paclitaxel doses and incubated for $24 \mathrm{~h}$. The 
cells were dissociated from the culture plate and collected by centrifugation at room temperature $1,000 \mathrm{x}$ g for $5 \mathrm{~min}$, the cell pellets were re-suspended in $500 \mu \mathrm{l}$ binding buffer (containing $5 \mu \mathrm{l}$ FITC Annexin V and $5 \mu \mathrm{l}$ PI; Nanjing KeyGen Biotech Co., Ltd., Nanjing, China), and incubated for $20 \mathrm{~min}$ at room temperature in the dark. Apoptotic cells were analyzed by flow cytometry (BD Biosciences, Franklin Lakes, NJ, USA) using FACSDiva Version 6.1.3 software (BD Biosciences) after $1 \mathrm{~h}$.

Determination of intracellular ROS levels. CHMm cells were treated with $(0,0.01,0.1$ and $1 \mu \mathrm{M})$ paclitaxel, with or without $5 \mathrm{mM} \mathrm{N}$-acetyl-L-cysteine (NAC). After a treatment period of $24 \mathrm{~h}$, cells were digested with $0.25 \%$ trypsin. Levels of ROS were measured using a dichlorodihydrofluorescein diacetate (DCFH-DA) detection kit, according to the manufacturer's protocol (Beyotime Institute of Biotechnology). Briefly, cells were collected $\left(1 \times 10^{6} / \mathrm{ml}\right)$, washed with serum free DMEM and incubated with $10 \mathrm{mM}$ DCFH-DA at $37^{\circ} \mathrm{C}$ for $20 \mathrm{~min}$. Stained cells were washed three times and re-suspended in serum-free DMEM. Intracellular ROS oxidized the non-fluorescent DCFH resulting in conversion to the fluorescent DCF molecule. The levels of ROS were measured using a fluorescent microplate reader using a reference wavelength of $490 \mathrm{~nm}$ and a detection wavelength of $570 \mathrm{~nm}$.

Measurement of superoxide dismutase (SOD) activity and malondialdehyde (MDA) content. CHMm cells were dissociated from the culture plates using $0.25 \%$ trypsin, collected and rinsed with cold PBS. Cells were lysed with $0.05 \mathrm{M}$ Tris- $\mathrm{HCl}$ (Beijing Biotopped Science \& Technology Co., Ltd., Being, China) extraction buffer on ice. The cell lysates were centrifuged at $4^{\circ} \mathrm{C} 12,000 \times \mathrm{g}$ for $10 \mathrm{~min}$. The resulting cell lysates were used to assess the SOD activity and MDA content, which were measured according to the manufacturer's protocols (Nanjing Jiancheng Bioengineering Institute, Nanjing, China).

Western blotting. Western blot analysis was used to evaluate the expression level of cytochrome c (cyt-c; cat. no. WL02410; 1:500), cyclin B1 (cat. no. WL02310; 1:500), Bcl-2 (cat. no. WL01556; 1:500), apoptosis regulator BAX (Bax, (cat. no. WL01637; 1:500), cyclin dependent kinase inhibitor 1 (P21; cat. no. WL0362; 1:500; Wanleibio Co., Ltd., Shenyang, China), tumor protein 53 (P53; cat. no. 9282; 1:750) and cleaved-caspase-3 (cat. no. 9664; 1:750; CST Biological Reagents Co., Ltd., Shanghai, China); AKT (cat. no. E1A6259; 1:500), p-AKT (ser-124; cat. no. E1A3260; 1:500), P38 (cat. no. E1A6456; 1:500), p-p38 (tyr-182; cat. no. E1A3455; 1:500), p-ribosomal protein S6 kinase (P70S6K; ser-229; cat. no. E1A3226; 1:500), P70S6K (cat. no. E1A6226; 1:500), p-90 kDa ribosomal protein S6 kinase 1 (P90RSK; ser-352; cat. no. E011113; 1:500) and P90RSK (cat. no. E110536; 1:500; Enjing Biotech Co., Ltd., Nanjing, China) in CHMm cells following treatment with paclitaxel. The synergistic effects of paclitaxel and inhibitors of cell signaling molecules in CHMm cells. CHMm cells were incubated in serum-free medium with LY294002 $(20 \mu \mathrm{M})$ or SB203580 $(20 \mu \mathrm{M})$ for $1 \mathrm{~h}$ and subsequently incubated with paclitaxel $(1 \mu \mathrm{M})$ for $30 \mathrm{~min}$ at $37^{\circ} \mathrm{C}$. Then, the cells were lysed with cell RIPA lysis buffer (Beyotime Institute of Biotechnology) to obtain a total protein lysate. For the detection of cyt-c, the collected cells were processed using a mitochondria isolation kit (Beyotime Institute of Biotechnology) to obtain the cytosolic component and mitochondrial pellet. Protein concentration from each culture was determined using a bicinchoninic acid protein assay kit (Beyotime Institute of Biotechnology). Proteins were denatured by boiling for $10 \mathrm{~min}$ and separated using 10-15\% SDS-PAGE. Subsequently, the resolved protein bands were transferred onto nitrocellulose membranes and blocked with $5 \%$ skim milk at room temperature for $1 \mathrm{~h}$. The membranes were incubated with the primary antibodies at $4^{\circ} \mathrm{C}$ overnight. The membranes were subsequently washed three times for $10 \mathrm{~min}$ each in TBST buffer (1\% Tween-20) and incubated with horseradish peroxidase-labeled secondary antibodies (goat anti-rabbit, cat. no. ZB2301, 1:2,000; goat anti-mouse, cat. no. ZB2305, 1:2,000; OriGene Technologies, Inc., Beijing, China) at $37^{\circ} \mathrm{C}$ for $1 \mathrm{~h}$. The immunoreactive bands were visualized using Tanon ${ }^{\mathrm{TM}}$ High-sig ECL Substrate (Tanon Science and Technology Co., Ltd., Shanghai, China) and images of membranes were captured using Chemidoc XRS system (Bio-Rad Laboratories, Inc., Hercules, CA, USA). Total protein and $\beta$-actin protein (cat. no. TA09; 1:1,000; OriGene Technologies, Inc.) served as internal controls. Relative protein levels were quantified using ImageJ 1.48 software (National Institutes of Health, Bethesda, MD, USA).

Statistical analysis. Data are presented as the mean \pm standard deviation. Analyses of differences between groups were carried out using one-way analysis of variance followed by Tukey's multiple comparison test in the GraphPad Prism 5.0 software package (GraphPad Software, Inc., La Jolla, CA, USA). All experiments were replicated at least three times. $\mathrm{P}<0.05$ was considered to indicate a statistically significant difference.

\section{Results}

Effects of paclitaxel on growth and cytotoxicity in $\mathrm{CHMm}$ cells. The efficacy of paclitaxel-mediated inhibition of $\mathrm{CHMm}$ cell growth was assessed using MTT assay. The data indicated that with increasing concentration of paclitaxel $(0,0.01,0.1$ and $1 \mu \mathrm{M})$, cell viability decreased in a dose-dependent manner, compared with the control group ( $\mathrm{P}<0.01$; Fig. 1A). Furthermore, treatment with paclitaxel enhanced LDH activity in $\mathrm{CHMm}$ cells in a dose-dependent manner ( $\mathrm{P}<0.01$; Fig. $1 \mathrm{~B})$. These data indicate that paclitaxel effectively suppressed CHMm cell proliferation.

Morphological alterations characteristic of apoptosis induced by paclitaxel in $\mathrm{CHMm}$ cells. To further investigate the effects of paclitaxel on CHMm cells, the morphological alterations were observed using an inverted phase contrast microscope. In the paclitaxel treatment group at $24 \mathrm{~h}$, irregularities in cell growth and development were observed. Specifically, the cells appeared oval or round with no or one nucleus. Detached or necrotic cells, reductions in the numbers of adherent cells and poor cell refraction were observed in a dose dependent manner (Fig. 1C). The results of AO/EB staining demonstrated that the control group cells stained light green with few apoptotic cell present. Following response to paclitaxel, a notable increase in cells with intense green, orange and red staining were observed, which represented cells undergoing early 

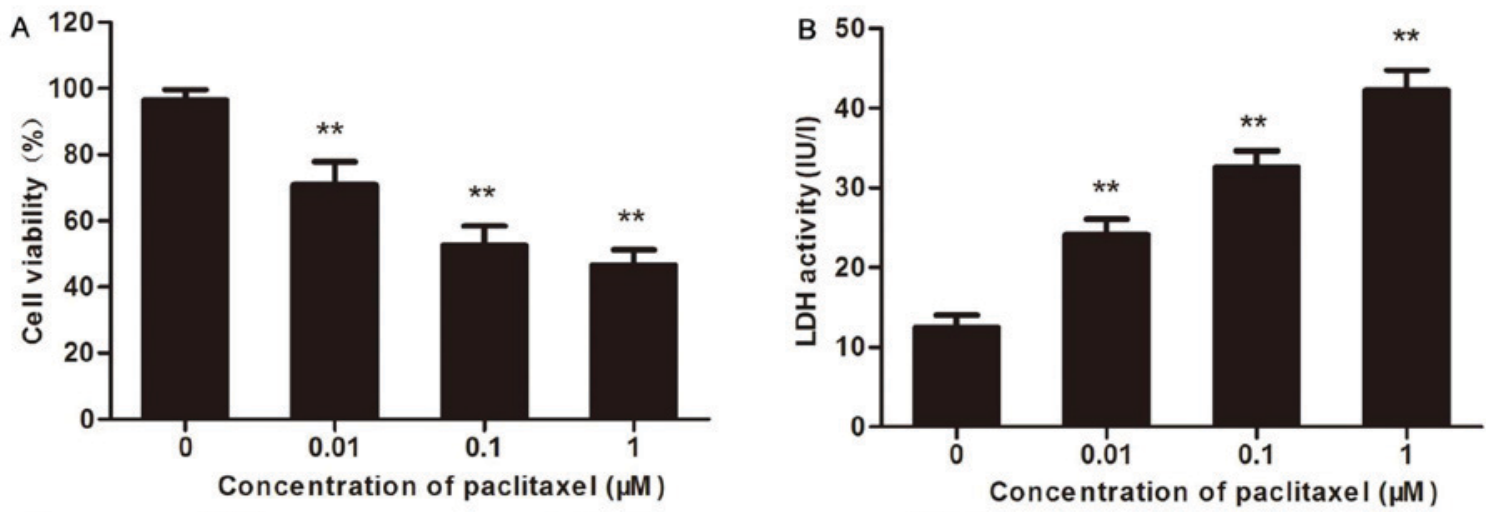

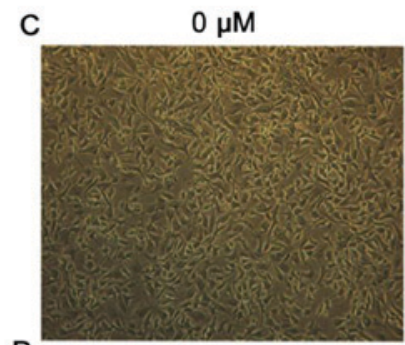

$0.01 \mu \mathrm{M}$

$0.1 \mu \mathrm{M}$
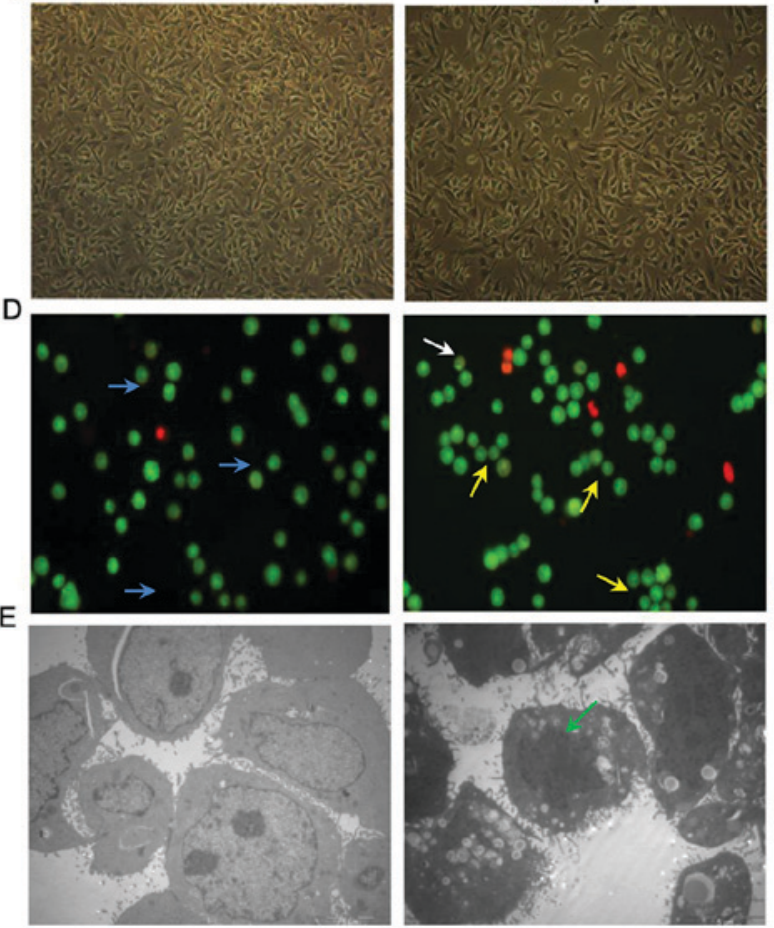
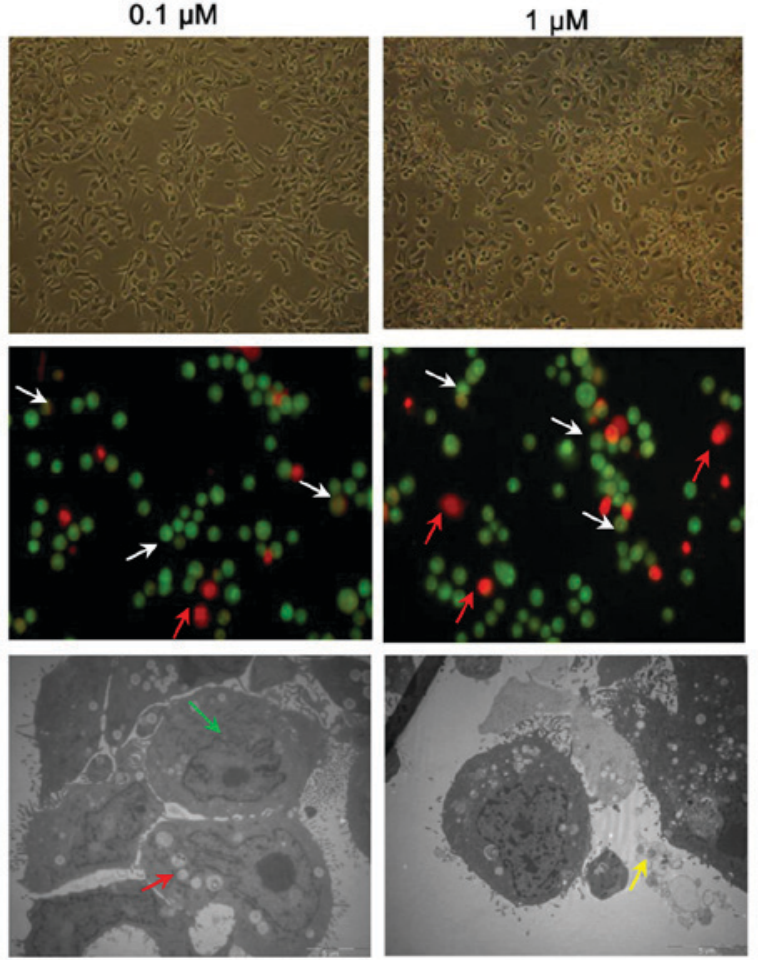

Figure 1. Effects of paclitaxel on CHMm cell viability and morphology. (A) The effect of paclitaxel on CHMm cell viability was assessed by MTT assay after $24 \mathrm{~h}$ of treatment. (B) The effect of paclitaxel on LDH levels in CHMm cells was evaluated by the LDH assay following $24 \mathrm{~h}$ of treatment. (C) Cell morphology was observed by light microscopy (magnification, x100). (D) Acridine orange/ethidium bromide staining. Normal cells exhibited green staining (blue arrows), early apoptotic cells were bright green (yellow arrows), and late apoptotic cells were orange (white arrow); necrotic cells were red (red arrow). Magnification, x200. (E) Morphological alterations of CHMm cells following treatment with paclitaxel for $24 \mathrm{~h}$ under transmission electron microscope. Cell chromatin condensation and marginalization (green arrow), intracellular vacuolization (red arrow), the emergence of apoptosis bodies (yellow arrow) were observed (magnification, $\mathrm{x} 6,000$ ). Data are presented as the mean \pm standard deviation from results of three individual experiments. ${ }^{* *} \mathrm{P}<0.01 \mathrm{vs} .0 \mu \mathrm{M}$. LDH, lactate dehydrogenase.

apoptosis, late apoptosis and necrosis, respectively (Fig. 1D). The morphology of apoptotic cells was observed by TEM. The observed characteristics included marginalization and condensation of chromatin, nuclear fragmentation, intracellular vacuolization and emergence of apoptotic bodies (Fig. 1E).

The effect of paclitaxel on cell-cycle arrest and apoptosis in CHMm cells by flow cytometry. The data collected using flow cytometry demonstrated that the percentage of cells arrested in $\mathrm{G}_{2} / \mathrm{M}$-phase significantly increased in the groups treated with $1 \mu \mathrm{M}$ paclitaxel, compared with the untreated controls, after $24 \mathrm{~h}(\mathrm{P}<0.01)$. The effect of $1 \mu \mathrm{M}$ paclitaxel was more pronounced compared with $0.1 \mu \mathrm{M}$ paclitaxel (Fig. 2A and B). The number of apoptotic CHMm cells increased in a dose dependent manner after $24 \mathrm{~h}$ of treatment with paclitaxel. The proportion of apoptotic cells reached the greatest value when cells were treated with $1 \mu \mathrm{M}$ paclitaxel. Treatment with $5 \mathrm{mM}$ NAC had significant inhibitory effect the paclitaxel-induced apoptosis in CHMm cells. These results indicate that paclitaxel likely promoted apoptosis in the CHMm cells, through a process that may be associated with increased oxidative stress, ultimately arresting the cell cycle in the $\mathrm{G}_{2} / \mathrm{M}$-phase (Fig. 2C and D).

Effect of paclitaxel on the ROS, SOD and MDA in CHMm cells. Excess ROS production is an early event that triggers cell apoptosis. To determine the involvement of ROS, SOD and MDA during paclitaxel-induced apoptosis on $\mathrm{CHMm}$ cells. ROS levels were evaluated using a DCFH-DA probe, compared with the control group, the levels of ROS and 
A

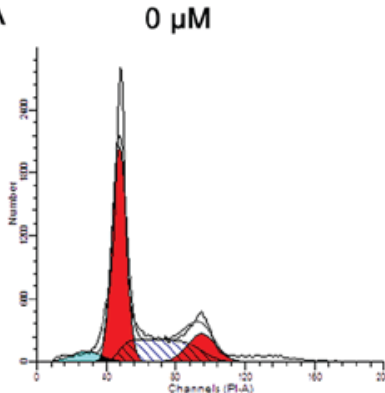

B

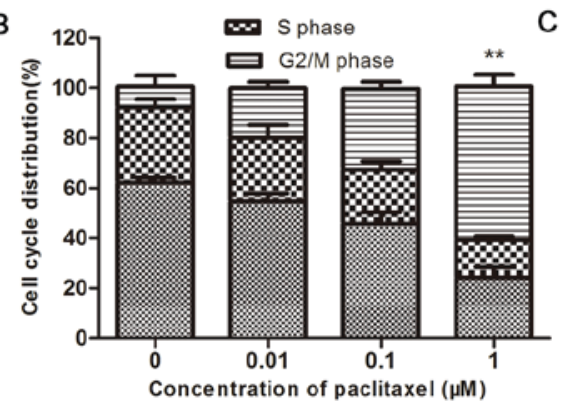

$0.1 \mu \mathrm{M}$

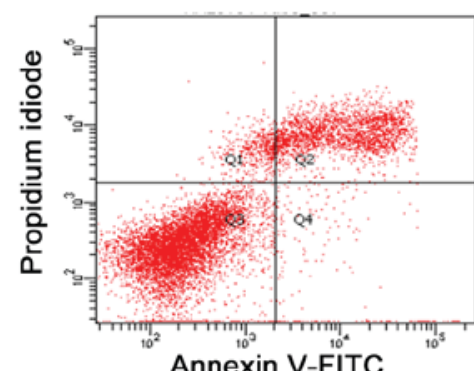

D
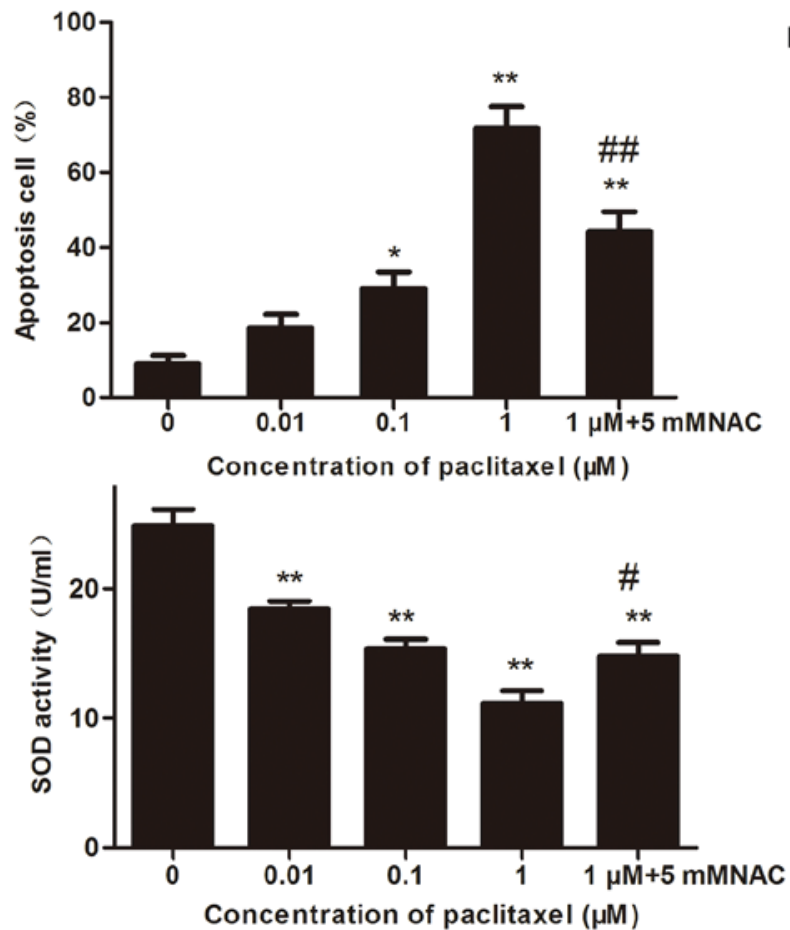

$0.1 \mu \mathrm{M}$

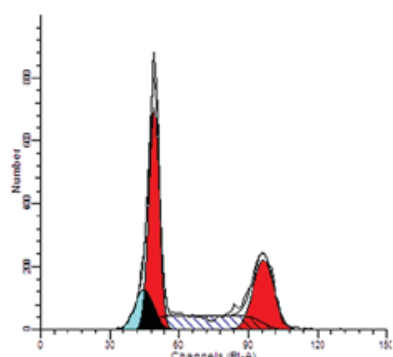

$0 \mu \mathrm{M}$

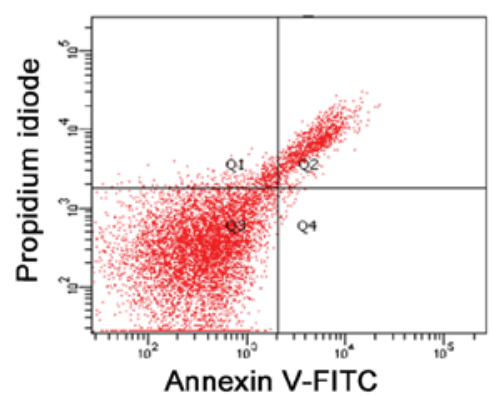

$1 \mu \mathrm{M}$
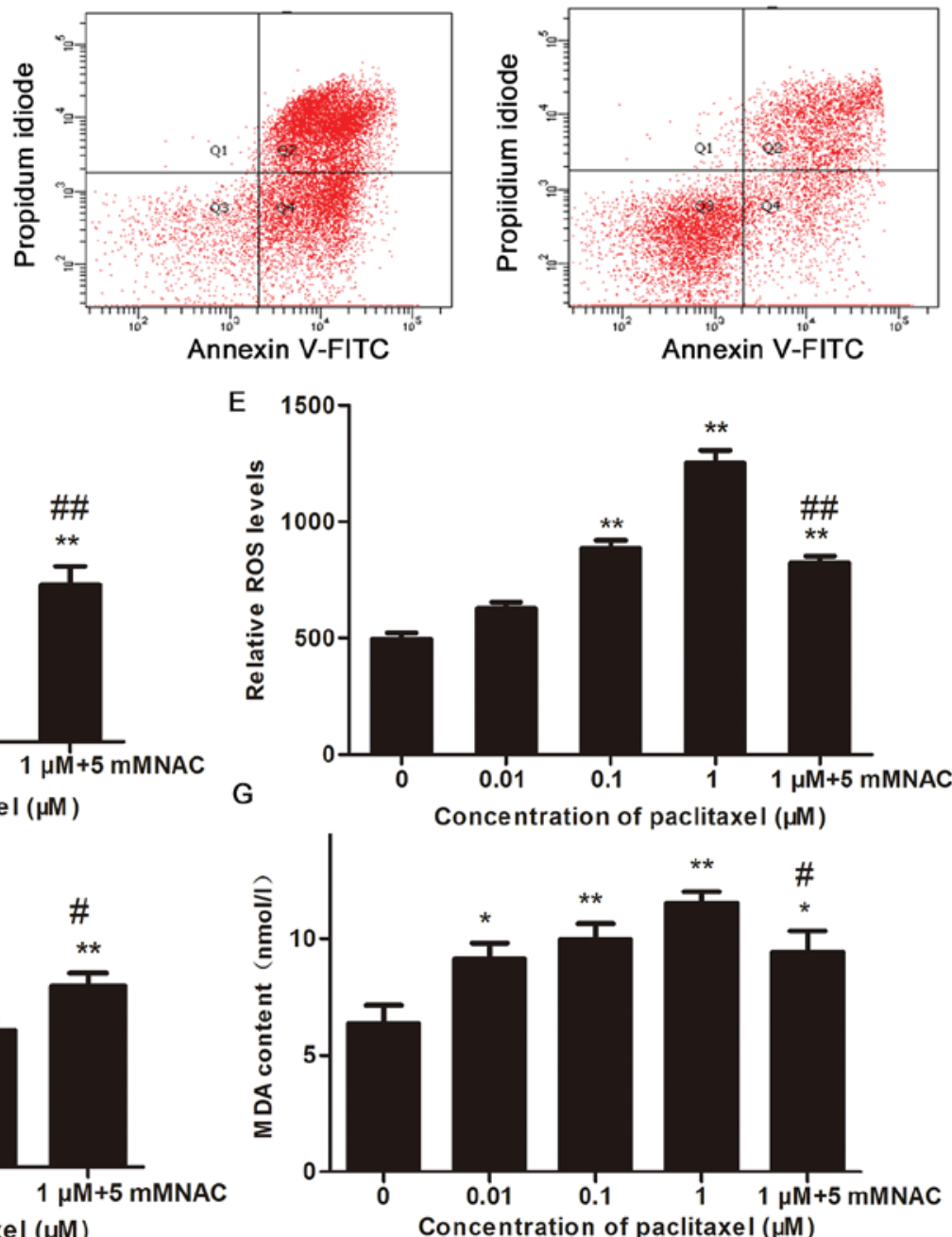

Figure 2. Effects of paclitaxel on apoptosis, cell cycle distribution and levels of ROS, SOD and MDA in CHMm cells. (A) Cell-cycle distribution was assayed with PI staining by flow cytometry after $24 \mathrm{~h}$ of treatment with paclitaxel. (B) Percentage of cells in $\mathrm{G}_{0} / \mathrm{G}_{1}, \mathrm{~S}$ or $\mathrm{G}_{2} / \mathrm{M}$-phases of the cell cycle. Data are presented as the mean \pm standard deviation of triplicates. (C) Apoptotic cells were determined by flow cytometry with Annexin V-fluorescein isothiocyanate/PI staining. (D) Quantitative analysis of the results of flow cytometry analysis presented the mean \pm standard deviation of triplicates. (E) ROS levels were measured by DCFH-DA staining. (F) SOD activity and (G) MDA content in cells treated with paclitaxel was estimated compared with the control group. ${ }^{*} \mathrm{P}<0.05$ and ${ }^{* *} \mathrm{P}<0.01$ vs. $0 \mu \mathrm{M}$. ${ }^{\#} \mathrm{P}<0.05$ and ${ }^{\# \#} \mathrm{P}<0.01,1 \mu \mathrm{M}$ paclitaxel vs. $1 \mu \mathrm{M}+5 \mathrm{Mm}$ NAC. ROS, reactive oxygen species; SOD, superoxide dismutase; MDA, malondialdehyde; NAC, N-acetyl-L-cysteine; PI, propidium iodide. 

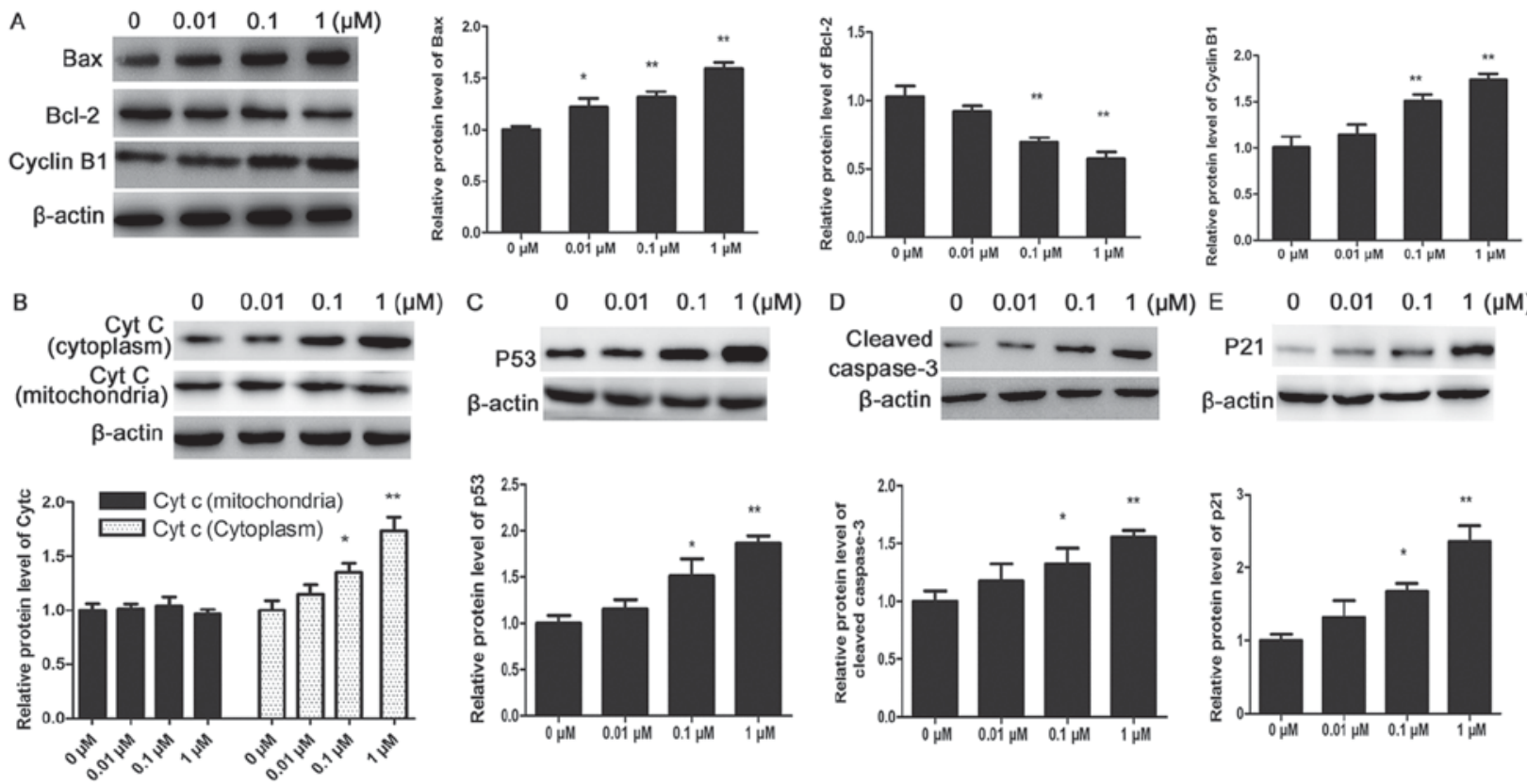

Figure 3. Effects of paclitaxel on expression of apoptosis-associated proteins in CHMm cells. Expression levels of (A) Bax, Bcl-2 and cyclin B1, (B) cytc-, (C) P53, (D) cleaved caspase-3 and (E) P21 protein in CHMm cells treatment with paclitaxel were estimated by western blot analysis after 24 h. $\beta$-actin was used as the protein loading control. Data are presented as the mean \pm standard deviation of triplicates. ${ }^{*} \mathrm{P}<0.05$ and ${ }^{* *} \mathrm{P}<0.01$ vs. $0 \mu \mathrm{M}$. Bax, apoptosis regulator $\mathrm{BAX}$; cyt-c, cytochrome c; Bcl-2, apoptosis regulator Bcl-2; P53, tumor protein 53; P21, cyclin dependent kinase inhibitor 1.

MDA in the CHMm cells treated with paclitaxel were significantly increased $(\mathrm{P}<0.05$ and $\mathrm{P}<0.01)$, whereas SOD activity decreased significantly in a dose-dependent manner $(\mathrm{P}<0.01$; Fig. 2E-G). However, compared with the $1 \mu \mathrm{M}$ group, the ROS $(\mathrm{P}<0.01)$ and MDA $(\mathrm{P}<0.05)$ contents in the $5 \mathrm{mM}$ NAC-treated cells decreased (Fig. 2E and G). By contrast, compared with the $1 \mu \mathrm{M}$ group, SOD activity in $5 \mathrm{mM}$ NAC-treated cells was increased $(\mathrm{P}<0.05$; Fig. $2 \mathrm{~F})$. These results indicate that paclitaxel may lead to increased generation of ROS in CHMm cells and excessive accumulation of intracellular ROS can cause oxidative stress damage and promote apoptosis.

Effect of paclitaxel on the expression of apoptosis-associated proteins in $\mathrm{CHMm}$ cells. To further determine the cellular basis of the apoptotic response observed in CHMm cells, the expression of apoptosis-associated proteins was detected by western blot analysis. P53, a tumor suppressor gene, is upregulated in response to several cellular processes, including DNA damage and oxidative stress, which directly or indirectly regulate mitochondrial physiology $(23,24)$. The results of the present study demonstrated that paclitaxel may promote expression of P53 protein in CHMm cells. Bcl-2 family members serve regulatory roles in the mitochondrial dysfunction during programed cell death (25). Treatment with paclitaxel decreased the expression of $\mathrm{Bcl}-2$ and increased the expression of Bax in a dose-dependent manner in $\mathrm{CHMm}$ cells, as determined by western blot analysis. The results indicated that expression levels of cyt-c (cytoplasmic), Bax and cleaved caspase-3 were upregulated whereas the expression of Bcl-2 was downregulated following a $24 \mathrm{~h}$ paclitaxel treatment in CHMm cells, and these expression patterns were dose-dependent, and differences were statistically significant compared with the control group $(\mathrm{P}<0.05$ and $\mathrm{P}<0.01$; Fig. 3$)$. These results indicate that paclitaxel-induced cell apoptosis is medicated by increased activation of pro-apoptotic protein Bax, release of cyt-c to cytosol and increased levels of cleaved caspase-3 in CHMm cells.

Effects of paclitaxel on the AKT/MAPK signaling pathway in $C H M m$ cells. The aim of subsequent experiments was to confirm whether the effect of paclitaxel on the viability of CHMm cells was associated with alterations in the AKT/MAPK signal transduction pathways. Western blot analysis indicated that the level of p-P38 and p-P90RSK was significantly increased in the paclitaxel-treated groups, in a dose-dependent manner $(\mathrm{P}<0.05$ and $\mathrm{P}<0.01)$. By contrast, expression levels of total P38 and P90RSK proteins remained unaltered. In addition, treatment with paclitaxel resulted in decreased levels of p-AKT and p-P70S6K in a dose-dependent manner $(\mathrm{P}<0.05$ and $\mathrm{P}<0.01$; Fig. 4). The above results indicate that paclitaxel-induced apoptosis is likely mediated the AKT/MAPK signaling transduction pathway in $\mathrm{CHMm}$ cells.

Effects of treatment with paclitaxel in combination with inhibitors of cell signaling proteins on the AKT/MAPK signal transduction in CHMm cells. To determine whether the reduction in viability of $\mathrm{CHMm}$ cells following treatment with paclitaxel was mediated by the AKT/MAPK pathway, cell viability was measured in CHMm cells treated with $1 \mu \mathrm{M}$ paclitaxel alone or in combination with pharmacological inhibitors including LY294002 (PI3K/AKT inhibitor; $20 \mu \mathrm{M}$ ) or SB203850 (P38 inhibitor; $20 \mu \mathrm{M})$. Compared with control cells, viability of CHMm cells to $45 \%(\mathrm{P}<0.01)$ when treated with paclitaxel alone. Compared with cells either treated with paclitaxel alone or the pharmacological inhibitors alone, CHMm cells treated in combination exhibited a significant reduction in viability $(\mathrm{P}<0.05$; Fig. $5 \mathrm{~A})$. Furthermore, the 
A
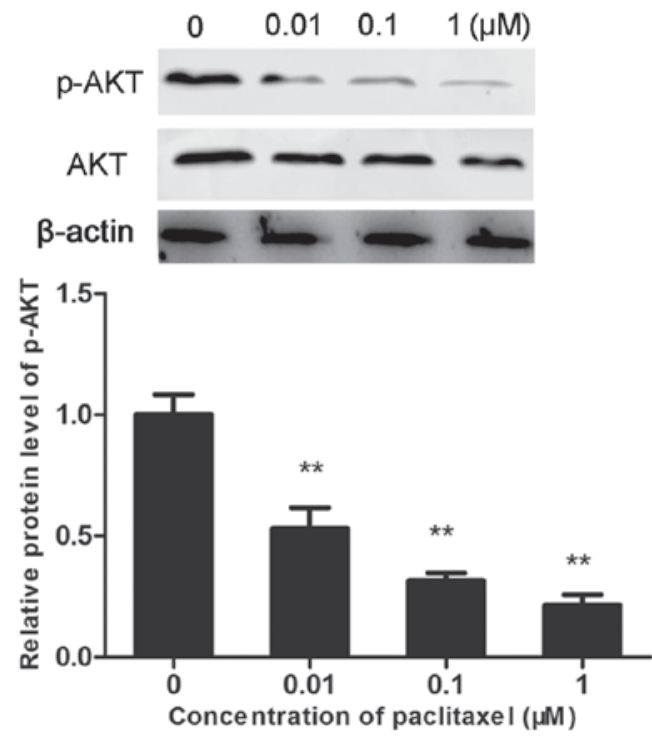

C
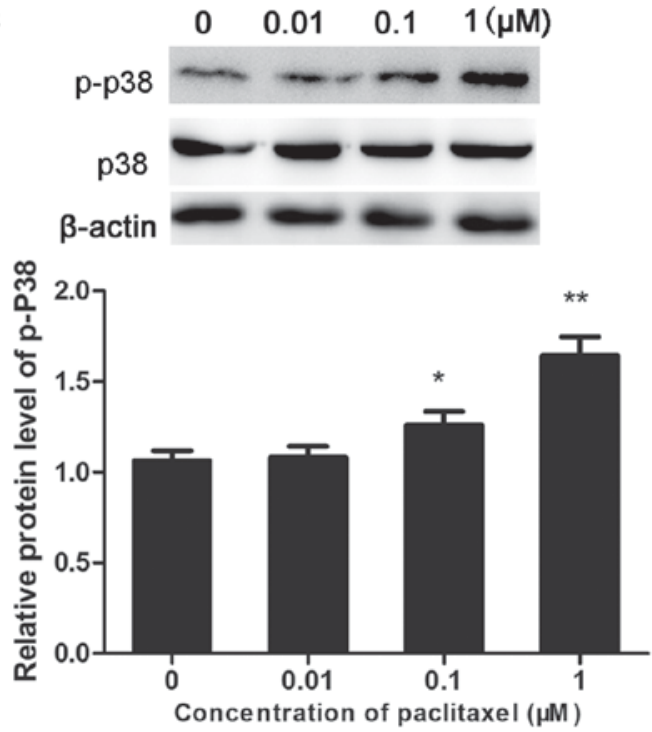

B
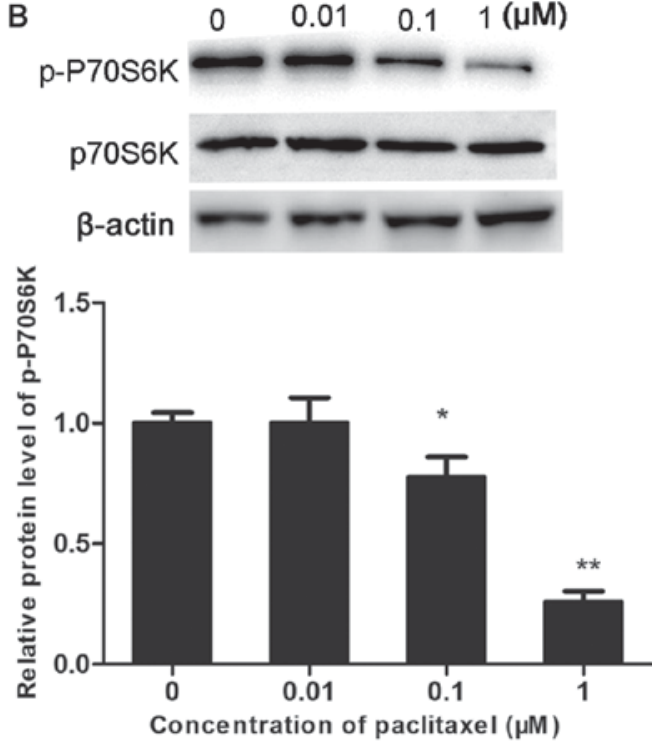

D
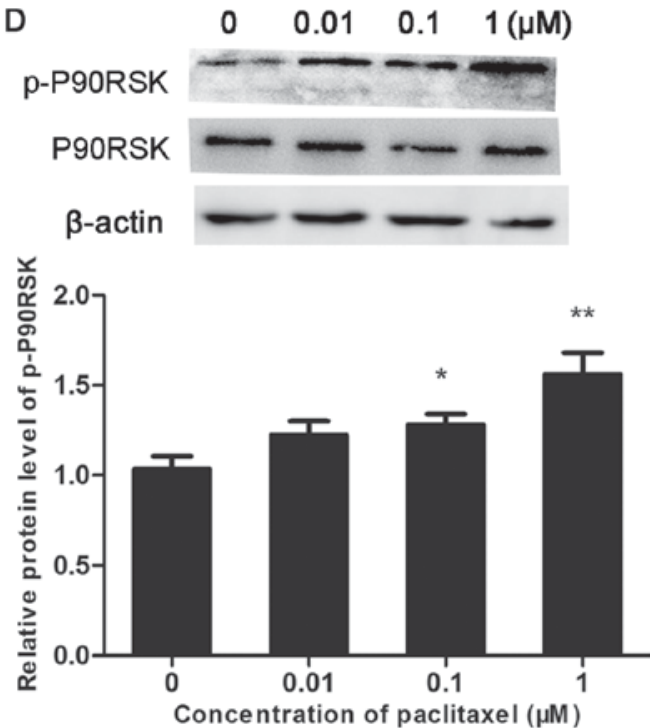

Figure 4. Effects of paclitaxel on the AKT/mitogen-activated protein kinase signal transduction pathway in CHMm cells. Levels of (A) p-AKT, (B) p-P70S6K, (C) p-P38 and (D) p-P90RSK proteins in CHMm cells treatment with paclitaxel were estimated by western blot analysis after $24 \mathrm{~h}$. The total protein was used as loading control. Data are presented as the mean \pm standard deviation of triplicates. " $\mathrm{P}<0.05$ and ${ }^{* *} \mathrm{P}<0.01$ vs. the control group. P90RSK, $90 \mathrm{kDa}$ ribosomal protein S6 kinase 1; P70S6K, ribosomal protein S6 kinase; p, phospho; AKT, RAC- $\alpha$ serine/threonine-protein kinase.

expression levels of relevant signaling proteins in $\mathrm{CHMm}$ cells following treatment with paclitaxel or pharmacological inhibitors were determined by western blot analysis. The AKT phosphorylation following paclitaxel treatment alone was further inhibited using SB203580 and LY294002 in CHMm cells, and expression of p-P70S6K was inhibited by SB203580 and LY294002 in CHMm cells. Compared with the paclitaxel treatment group, activation of p-P38 was completely suppressed by SB203580 $(\mathrm{P}<0.05)$. The $90 \mathrm{kDa}$ ribosomal S6 kinases are a family of Ser/Thr kinases that regulate various cellular growth processes, as downstream molecule of the Ras-MAPK and ERK1/2 signaling pathway (26), p-P90RSK was inhibited by SB203580 and LY294002 (Fig. 5B-E), The above results suggest that the molecular mechanisms underlying the inhibition of CHMm cells proliferation by paclitaxel was mediated by inhibition of the PI3K/ AKT signaling and activation of MAPK signaling pathway.

\section{Discussion}

Although numerous studies have revealed the anticancer effect of paclitaxel in a number of human cancer cells, including breast cancer, to the best of the authors' knowledge, the role of paclitaxel in canine mammary gland tumor has not been studied before (8). In the present study, the effect of paclitaxel on the viability of CHMm cells was assessed by MTT and LDH release assay in vitro. The results demonstrated that paclitaxel inhibited proliferation of CHMm cells in vitro, in a dose-dependent manner. In addition, as the paclitaxel-mediated activity of LDH increased, cellular viability was inhibited in a dose-dependent manner.

Apoptosis is a proactive cell death process in which cells undergo a certain stimulus to maintaining the stability of the internal environment, The morphological alterations of apoptosis are characterized by cell shrinkage, chromatin 
A
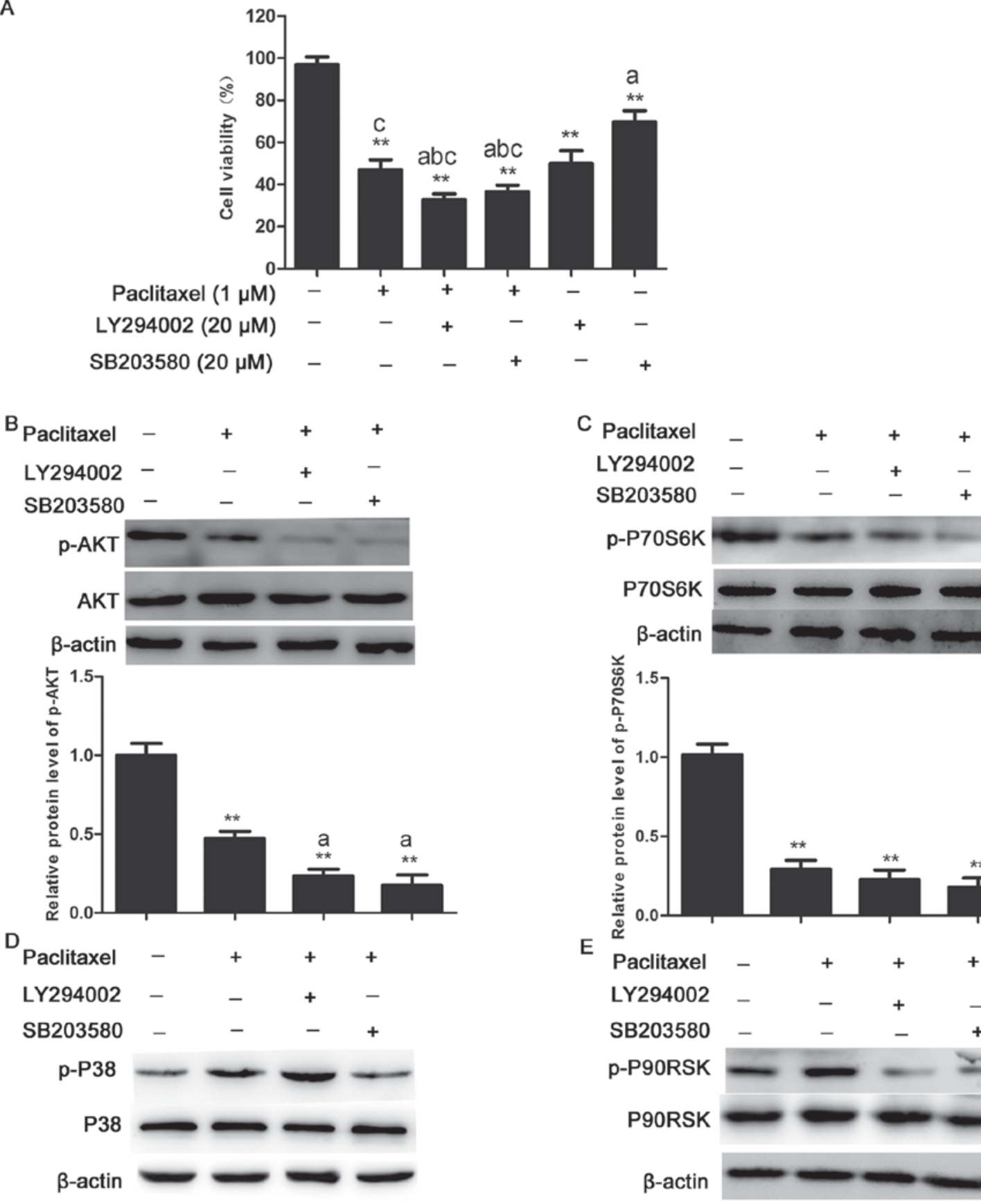

Paclitaxel $(1 \mu \mathrm{M})$ LY294002 (20 $\mu \mathrm{M})$ SB203580 $(20 \mu \mathrm{M})$
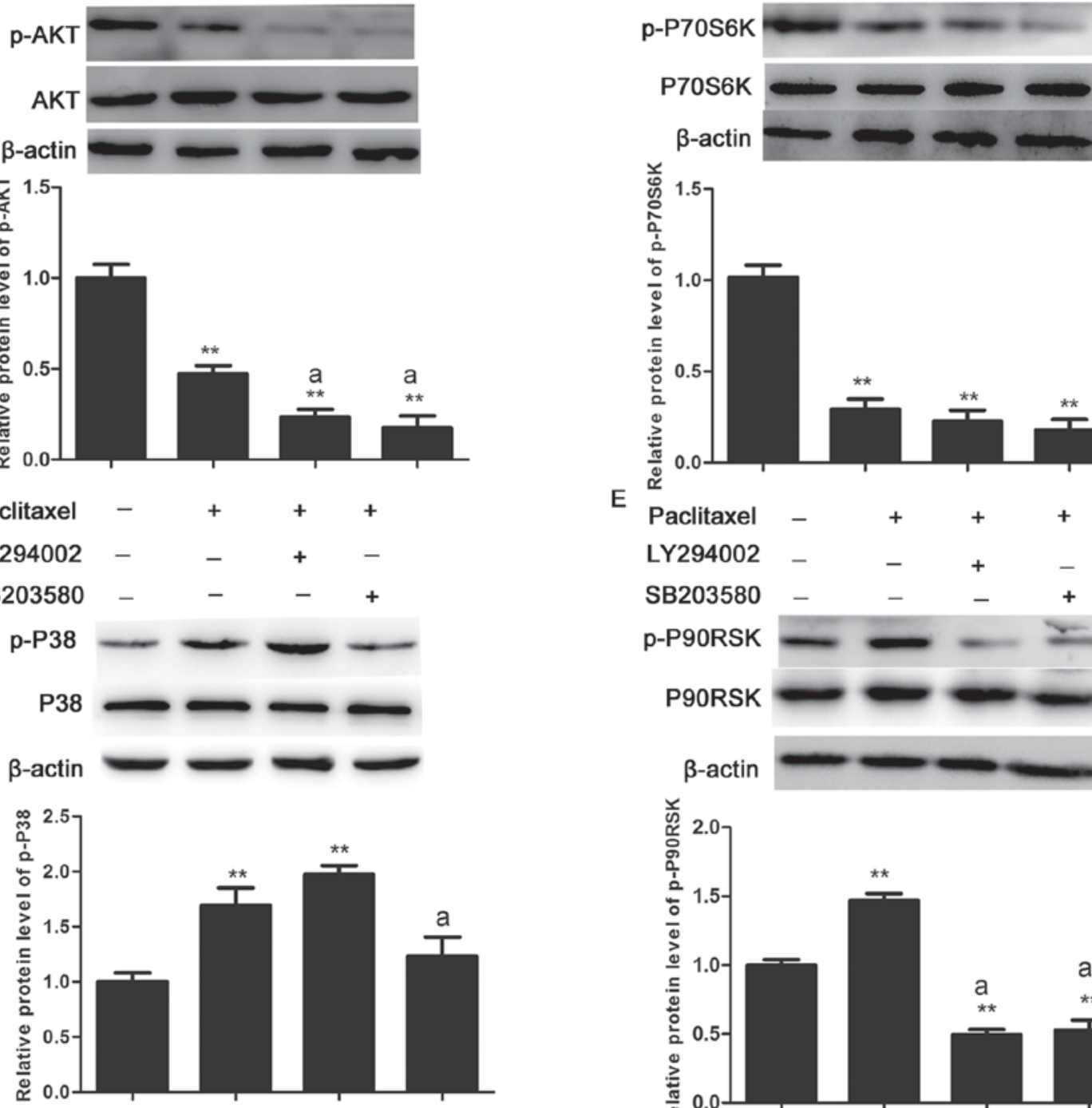

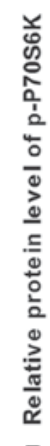

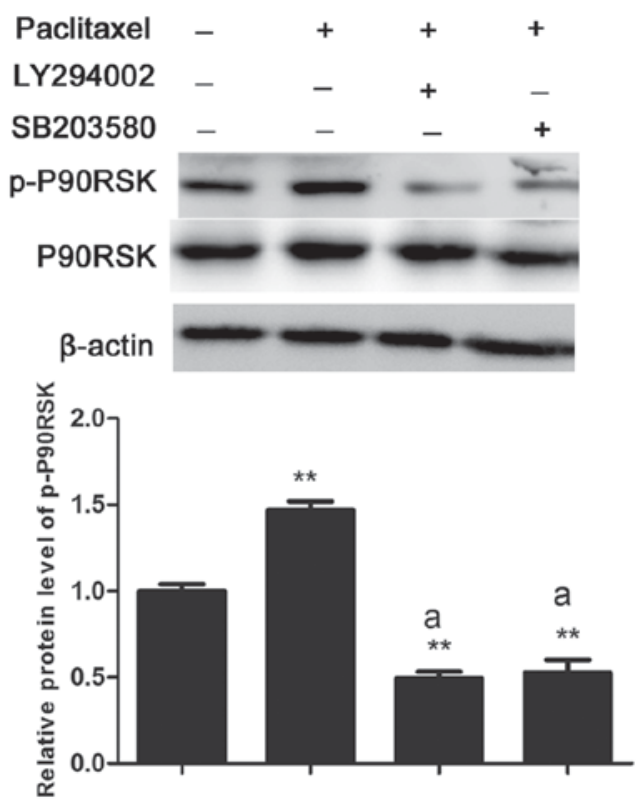

Figure 5. Effects of combined treatment with paclitaxel and inhibitors of cell signaling proteins on the AKT/mitogen-activated protein kinase signal transduction pathway in CHMm cells. (A) Inhibition of CHMm cell viability was observed in cells treated with paclitaxel and either LY294002 or SB203580, or their combination. CHMm cells were treated with paclitaxel $(1 \mu \mathrm{M})$ and LY294002 $(20 \mu \mathrm{M})$, SB203580 $(20 \mu \mathrm{M})$ or their combination for $24 \mathrm{~h}$. Cell viability was estimated using a proliferation assay. The synergistic effects of paclitaxel and inhibitors of cell signaling molecules in CHMm cells were investigated. CHMm cells were incubated in serum-free medium with LY294002 $(20 \mu \mathrm{M})$ or SB203580 $(20 \mu \mathrm{M})$ for $1 \mathrm{~h}$ and subsequently incubated with paclitaxel $(1 \mu \mathrm{M})$ for $30 \mathrm{~min}$. The effect of LY294002 and SB203580 in combination with paclitaxel on levels of (B) p-AKT, (C) p-P38, (D) p-P70S6K, and (E) p-P90RSK proteins was estimated by western blot analysis. Total protein was used as loading control. Data are presented as the mean \pm standard deviation of triplicates. ${ }^{* *} \mathrm{P}<0.01$ vs. untreated group. ${ }^{a} \mathrm{P}<0.05$ vs. compared with paclitaxel alone; ${ }^{b} \mathrm{P}<0.05$ vs. $\mathrm{LY} 294002$; ${ }^{\mathrm{C}} \mathrm{P}<0.05$ vs. SB203580 alone. p, phospho; P90RSK, $90 \mathrm{kDa}$ ribosomal protein S6 kinase 1; P70S6K, ribosomal protein S6 kinase; AKT, RAC- $\alpha$ serine/threonine-protein kinase. 


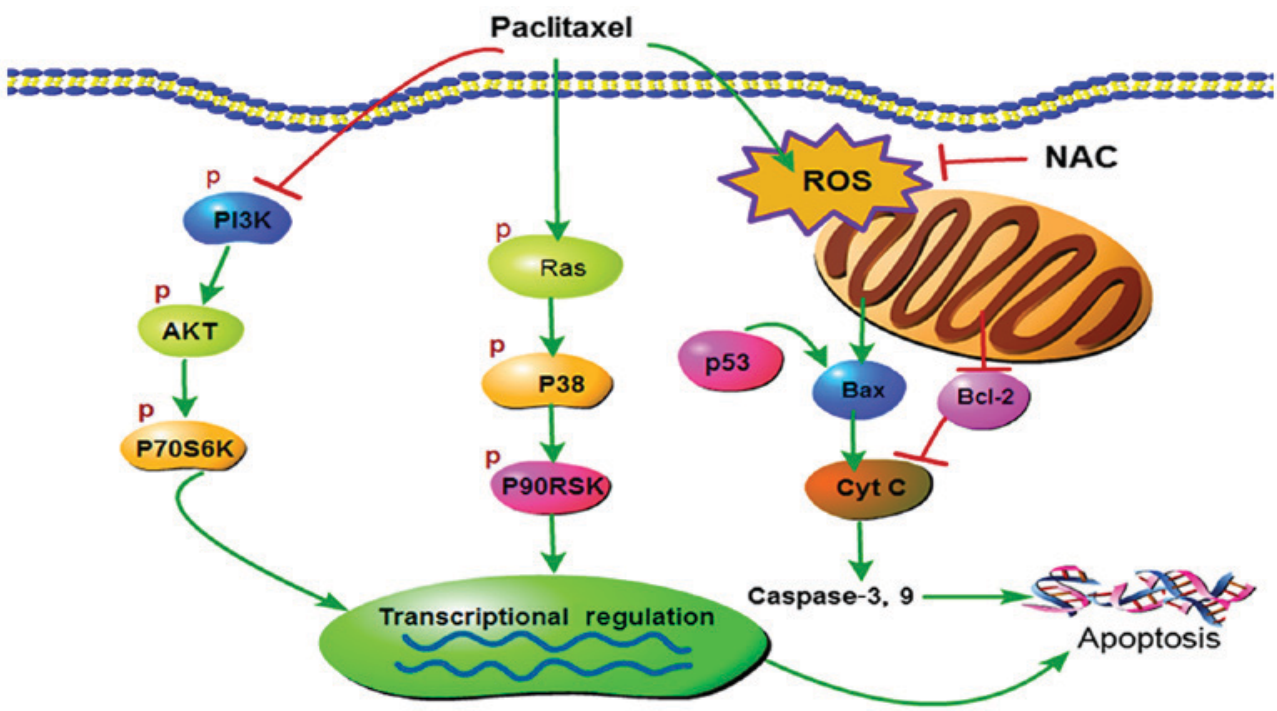

Figure 6. Graphical representation of the current working hypothesis regarding anticancer mechanisms induced by paclitaxel targeting multiple signaling pathways in CHMm cells. P, phospho; PI3K, phosphatidylinositol-4,5-bisphosphate 3-kinase; AKT, RAC- $\alpha$ serine/threonine-protein kinase; P70S6K, ribosomal protein S6 kinase; P90RSK, 90 kDa ribosomal protein S6 kinase 1; ROS, reactive oxygen species; NAC, N-acetyl-L-cysteine; Bax, apoptosis regulator BAX; Cyt c, cytochrome c; Bcl-2, apoptosis regulator Bcl-2; p53, tumor protein 53.

condensation, nuclear fragmentation, DNA degradation, and apoptotic body formation (27). Paclitaxel may arrest the division of cancer cells in the $\mathrm{G}_{2} / \mathrm{M}$-phase and elevate the expression of cyclinB1 $(28,29)$. In the present study, paclitaxel-treated CHMm cells exhibited morphological alterations characteristic of apoptosis, including cell shrinkage, intracellular vacuolization and chromatin condensation. Flow cytometry demonstrated that with increasing concentration of paclitaxel, the rates of apoptosis increased and cell cycle arrest in the $\mathrm{G}_{2} / \mathrm{M}$-phase was promoted. The P53 protein is a multifunctional transcription factor, associated with the occurrence and progression of numerous human tumors, mainly responsible for tumor cell apoptosis and cell cycle arrest $(23,24)$. Activation of P53 induces the expression of P21 and cyclinB1. Taken together, the above results suggest that paclitaxel-induced apoptosis and cell-cycle arrest in the $\mathrm{G}_{2} / \mathrm{M}$-phase in CHMm cells are likely to be associated with activation of P53 by DNA damage.

The Bcl-2 family of proteins, including Bcl-2, Bcl-like 1, $\mathrm{Bax}$ and $\mathrm{BH} 3$-interacting domain death agonist, have emerged as regulators of mitochondria-mediated apoptosis. An increase in the levels of pro-apoptosis proteins and/or a decrease in anti-apoptosis proteins can lead to a decrease in mitochondrial membrane potential and an opening of mitochondrial permeability transition pores, leading to cyt-c release from mitochondria into cytoplasm (30). A previous study revealed that paclitaxel can induce apoptosis of NB-1 cells, which may be mediated by downregulation of $\mathrm{Bcl}-2$ and upregulation of Bax (31).

In the present study, treatment of $\mathrm{CHMm}$ cells with paclitaxel resulted in a dose-dependent decrease in the levels of anti-apoptotic proteins Bcl-2 and a simultaneous increase in pro-apoptotic protein Bax. This alteration is known to be responsible for the concomitant execution phase of apoptosis, including the disruption of mitochondrial membrane potential (MMP), increased release of cyt-c into cytoplasm and cleavage of caspase-3 protein $(32,33)$.
Regulation of intrinsic apoptosis by Bcl-2 family proteins occurs through ROS production and is followed by reduction in the MMP level, which stimulates mitochondria to release proapoptotic molecules and results in activation of caspase-9 and $-3(34,35)$. The results of the present study demonstrated that levels of ROS and MDA were elevated, whereas SOD activity decreased following exposure to paclitaxel, when paclitaxel was administered with NAC, the levels of ROS and MDA were reduced, and SOD activity was increased. These results indicated that paclitaxel induced alterations in expression of apoptosis-associated proteins and generation of ROS. However, it remains to be elucidated whether mitochondria-dependent apoptosis induced by paclitaxel is mediated by ROS; the mechanism in which paclitaxel selectively induced apoptosis of CHMm cells has been defined but requires further investigation.

Paclitaxel induces apoptosis in various tumor types and regulates different signaling mechanisms in each $(12,17,36)$. The AKT/MAPK signaling pathway is hypothesized to have a role in sensitivity to paclitaxel and serve as a potential therapeutic target for treatment of gastric cancer (37). Previous results indicate that regulation of AKT/MAPK signaling pathways is closely associated with proliferation, migration and invasion of cancer cells during carcinogenesis (38). Based on the data presented in the present study, level of p-AKT and p-P70S6K signaling proteins decreased, whereas expression of the p-P38 and p-P90RSK signaling proteins increased in response to paclitaxel treatment in a dose-dependent manner. Furthermore, the present study demonstrated a synergistic effect when inhibitors LY294002 and SB203580 were administered in together with paclitaxel, significantly decreasing the viability of $\mathrm{CHMm}$ cells. Phosphorylation levels of P90RSK and P70S6K proteins were reduced by treatment with LY294002 and SB203580, the level of p-P38 was decreased significantly by treatment with SB203580 and p-AKT was decreased by LY294002. These results indicate that the paclitaxel-mediated suppression of proliferation 
of CHMm cells was likely the result of alterations to the AKT/MAPK pathway signaling.

In conclusion, to the best of our knowledge, the present study is the first to demonstrate that paclitaxel effectively suppresses proliferation of CHMm cells, induces cell cycle arrest in $\mathrm{G}_{2}$ /M-phase, increases the levels of MDA, ROS and reduces levels of SOD. Based on the results of the present study, treatment with paclitaxel induced cell apoptosis which may be mediated by downregulation of Bcl-2 and upregulation of Bax, and is likely associated with the inhibition of the PI3K/AKT signaling and activation of MAPK signaling pathways (Fig. 6). Collectively, the present study provides a theoretical basis for the clinical use of paclitaxel for treatment of canine mammary gland tumors.

\section{Acknowledgements}

The authors are grateful to Professor N. Sasaki, University of Tokyo for kindly providing the CHMm cell lines and thanks to the help of the Veterinary Surgery Laboratory at the College of Veterinary Medicine, Northeast Agricultural University.

\section{Funding}

The present study was supported by National Natural Science Foundation of China (grant no. 31372492) and by the National Key Research Projects, China (grant no. 2016YFD0501008).

\section{Availability of data and materials}

All data generated or analyzed during this study are included in this published article.

\section{Authors' contributions}

YL conceived and designed the experiments. XR, BZ, HC, MX and YW performed the experiments. XR analyzed the data and wrote the paper. YW and YL assisted in critically revised the manuscript.

\section{Ethics approval and consent to participate}

The present study was approved by the Laboratory Animal Ethical Committee of Northeast Agricultural University, Harbin, China.

\section{Consent for publication}

Not applicable.

\section{Competing interests}

The authors declare that they have no competing interests.

\section{References}

1. Torre LA, Bray F, Siegel RL, Ferlay J, Lortet-Tieulent J and Jemal A: Global cancer statistics, 2012. CA Cancer J Clin 65: 87-108, 2015

2. Sorenmo K: Canine mammary gland tumors. Vet Clin North Am Small Anim Pract 33: 573-596, 2003.
3. Vail DM and MacEwen EG: Spontaneously occurring tumors of companion animals as models for human cancer. Cancer Invest 18: 781-792, 2000.

4. Chauhan A, Sharma MM and Kumar K: Evaluation of surgical outcomes of oncoplasty breast surgery in locally advanced breast cancer and comparison with conventional breast conservation surgery. Indian J Surg Oncol 7: 413-419, 2016.

5. Shamsi $\mathrm{M}$ and Pirayesh Islamian J: Breast cancer: Early diagnosis and effective treatment by drug delivery tracing. Nucl Med Rev Cent East Eur 20: 45-48, 2017.

6. Jeong JY, Kim KS, Moon JS, Song JA, Choi SH, Kim KI, Kim TH and An HJ: Targeted inhibition of phosphatidyl inositol-3-kinase p1 $10 \beta$, but not $\mathrm{p} 110 \alpha$, enhances apoptosis and sensitivity to paclitaxel in chemoresistant ovarian cancers. Apoptosis 18: 509-520, 2013.

7. McGuire WP, Rowinsky EK, Rosenshein NB, Grumbine FC, Ettinger DS, Armstrong DK and Donehower RC: Taxol: A unique antineoplastic agent with significant activity in advanced ovarian epithelial neoplasms. Ann Intern Med 111: 273-279, 1989.

8. Quispe-Soto ET and Calaf GM: Effect of curcumin and paclitaxel on breast carcinogenesis. Int J Oncol 49: 2569-2577, 2016.

9. Holmes FA, Walters RS, Theriault RL, Forman AD, Newton LK, Raber MN, Buzdar AU, Frye DK and Hortobagyi GN: Phase II trial of taxol, an active drug in the treatment of metastatic breast cancer. J Natl Cancer Inst 83: 1797-1805, 1991.

10. Wang C, Wang R, Zhou K, Wang S, Wang J, Shi H, Dou Y, Yang D, Chang L, Shi X, et al: JD enhances the anti-tumour effects of low-dose paclitaxel on gastric cancer MKN45 cells both in vitro and in vivo. Cancer Chemoth Pharm 78: 971-982, 2016.

11. McGrogan BT, Gilmartin B, Carney DN and McCann A: Taxanes, microtubules and chemoresistant breast cancer. Biochim Biophys Acta 1785: 96-132, 2008.

12. Hu J, Zhang NA, Wang R, Huang F and Li G: Paclitaxel induces apoptosis and reduces proliferation by targeting epidermal growth factor receptor signaling pathway in oral cavity squamous cell carcinoma. Oncol Lett 10: 2378-2384, 2015.

13. Donaldson KL, Goolsby GL, Kiener PA and Wahl AF: Activation of p34cdc2 coincident with taxol-induced apoptosis. Cell Growth Differ 5: 1041-1050, 1994

14. Schiff PB, Fant J and Horwitz SB: Promotion of microtubule assembly in vitro by taxol. Nature 277: 665-667, 1979.

15. Ren L, Li Z, Dai C, Zhao D, Wang Y, Ma C and Liu C: Chrysophanol inhibits proliferation and induces apoptosis through $\mathrm{NF}-\kappa \mathrm{B} /$ cyclin $\mathrm{D} 1$ and $\mathrm{NF}-\kappa \mathrm{B} / \mathrm{Bcl}-2$ signaling cascade in breast cancer cell lines. Mol Med Rep 17: 4376-4382, 2018.

16. Kim GM, Kim S, Park HS, Kim JY, Nam S, Park S, Kim SI, Kim D and Sohn J: Chemotherapy-induced irreversible alopecia in early breast cancer patients. Breast Cancer Res Treat 163: 527-533, 2017.

17. Okano J and Rustgi AK: Paclitaxel induces prolonged activation of the Ras/MEK/ERK pathway independently of activating the programmed cell death machinery. J Biol Chem 276: 19555-19564, 2001.

18. Xu R, Sato N, Yanai K,Akiyoshi T,Nagai S, Wada J,Koga K, Mibu R, Nakamura M and Katano M: Enhancement of paclitaxel-induced apoptosis by inhibition of mitogen-activated protein kinase pathway in colon cancer cells. Anticancer Res 29: 261-270, 2009.

19. Tserga A, Chatziandreou I, Michalopoulos NV, Patsouris E and Saetta AA: Mutation of genes of the PI3K/AKT pathway in breast cancer supports their potential importance as biomarker for breast cancer aggressiveness. Virchows Arch 469: 35-43, 2016.

20. Son Y, Cheong YK, Kim NH, Chung HT, Kang DG and Pae HO: Mitogen-activated protein kinases and reactive oxygen species: How can ROS activate MAPK pathways? J Signal Transduct 2011: 792639, 2011.

21. Yang C, Lim W, Bazer FW and Song G: Myricetin suppresses invasion and promotes cell death in human placental choriocarcinoma cells through induction of oxidative stress. Cancer Lett 399: 10-19, 2017.

22. Morales-Cano D, Calviño E, Rubio V, Herráez A, Sancho P, Tejedor MC and Diez JC: Apoptosis induced by paclitaxel via Bcl-2, Bax and caspases 3 and 9 activation in NB4 human leukaemia cells is not modulated by ERK inhibition. Exp Toxicol Pathol 65: 1101-1108, 2013.

23. Sakashita F, Osada S, Takemura M, Imai H, Tomita H, Nonaka K, Takahashi T and Seishima M: The effect of p53 gene expression on the inhibition of cell proliferation by paclitaxel. Cancer Chemother Pharmacol 62: 379-385, 2008.

24. Norbury CJ and Zhivotovsky B: DNA damage-induced apoptosis. Oncogene 23: 2797-2808, 2004. 
25. Festjens N, van Gurp $M$, van Loo G, Saelens $X$ and Vandenabeele P: Bcl-2 family members as sentinels of cellular integrity and role of mitochondrial intermembrane space proteins in apoptotic cell death. Acta Haematol 111: 7-27, 2004.

26. Anjum R and Blenis J: The RSK family of kinases: Emerging roles in cellular signalling. Nat Rev Mol Cell Biol 9: 747-758, 2008.

27. Elmore S: Apoptosis: A review of programmed cell death. Toxicol Pathol 35: 495-516, 2007.

28. Ban JO, Hwang CJ, Park MH, Hwang IK, Jeong HS, Lee HP, Hyun BK, Kim JY, Youn HS, Ham YW, et al: Enhanced cell growth inhibition by thiacremonone in paclitaxel-treated lung cancer cells. Arch Pharm Res 38: 1351-1362, 2015.

29. Xia RL, Lu Y, Zhu LN, Zhang SF, Zhao FK and Fu CY: Different regulatory pathways are involved in the proliferative inhibition of two types of leukemia cell lines induced by paclitaxel. Oncol Rep 30: 1853-1859, 2013.

30. Yang J, Liu X, Bhalla K, Kim CN, Ibrado AM, Cai J, Peng TI, Jones DP and Wang X: Prevention of apoptosis by Bcl-2: Release of cytochrome c from mitochondria blocked. Science 275: 1129-1132, 1997

31. Nonaka M, Ikeda H, Fujisawa A, Uehara $M$ and Inokuchi $T$ : Induction of apoptosis by paclitaxel in human oral carcinoma cells. Int J Oral Maxillofac Surg 35: 649-652, 2006.

32. Suh DH, Kim MK, Kim HS, Chung HH and Song YS Mitochondrial permeability transition pore as a selective target for anti-cancer therapy. Front Oncol 3: 41, 2013.

33. Yang M, Wang B, Gao J, Zhang Y, Xu W and Tao L: Spinosad induces programmed cell death involves mitochondrial dysfunction and cytochrome $\mathrm{C}$ release in Spodoptera frugiperda $\mathrm{Sf9}$ cells. Chemosphere 169: 155-161, 2017.
34. Azad N, Iyer AK, Wang L, Lu Y, Medan D, Castranova V and Rojanasakul Y: Nitric oxide-mediated bcl-2 stabilization potentiates malignant transformation of human lung epithelial cells. Am J Respir Cell Mol Biol 42: 578-585, 2010.

35. Meshkini A and Yazdanparast R: Involvement of oxidative stress in taxol-induced apoptosis in chronic myelogenous leukemia K562 cells. Exp Toxicol Pathol 64: 357-365, 2012.

36. Akiyama M, Sowa Y, Taniguchi T, Watanabe M, Yogosawa S, Kitawaki J and Sakai T: Three combined treatment, a Novel HDAC inhibitor OBP-801/YM753, 5-Fluorouracil and paclitaxel, induces $\mathrm{G}_{2}$ phase arrest through the $\mathrm{p} 38$ pathway in human ovarian cancer cells. Oncol Res 25: 1245-1252, 2017.

37. Wu G, Qin XQ, Guo JJ, Li TY and Chen JH: AKT/ERK activation is associated with gastric cancer cell resistance to paclitaxel. Int J Clin Exp Pathol 7: 1449-1458, 2014.

38. Lim W, Park S, Bazer FW and Song G: Apigenin reduces survival of choriocarcinoma cells by inducing apoptosis via the PI3K/AKT and ERK1/2 MAPK pathways. J Cell Physiol 231: 2690-2699, 2016.

This work is licensed under a Creative Commons Attribution-NonCommercial-NoDerivatives 4.0 International (CC BY-NC-ND 4.0) License. 